\title{
Clinical Profile of Atypical Manifestations of Dengue Fever: Author's Reply
}

\author{
Sriram Pothapregada ${ }^{1}$
}

Received: 27 January 2016/Accepted: 24 February 2016/Published online: 2 April 2016

(C) Dr. K C Chaudhuri Foundation 2016

To the Editor : We thank Beuy Job and Viroj Wiwanitkit for highlighting clinically valid important points related to our study on atypical manifestations of dengue fever in children, an issue of great public health importance [1]. In our experience, we have seen a changing pattern of clinical presentation during recent epidemics with increase in atypical manifestations of dengue fever. Even though thrombocytopenia is the hallmark laboratory finding in dengue fever, but in our experience thrombocytopenia, bleeding manifestations and plasma leakage did not always correlate clinically [2]. Fever has been the predominant presentation in children admitted and screened for dengue fever in our study and in this context afebrile dengue is an interesting presentation as reported by the authors [3]. We agree with authors regarding the role of coinfections as the one of the probable factors for atypical manifestations in dengue illness. The awareness regarding atypical/unusual manifestations of dengue fever is grossly lacking among the clinicians. Since the case fatality rate in children with severe dengue infection is very high, there is a need to update the health care personnel and community at various forums, about the various atypical manifestations of dengue fever, its prompt recognition and early management in children.

\section{Compliance with Ethical Standards}

Conflict of Interest None.

Source of Funding None.

\section{References}

1. Pothapregada S, Kamalakannan B, Thulasingam M. Clinical profile of atypical manifestations of dengue fever. Indian J Pediatr. 2016. doi:10.1007/s12098-015-1942-9.

2. World Health Organization. Dengue hemorrhagic fever: diagnosis, treatment, prevention and control. 2nd ed. Geneva: World Health Organization; 2011.

3. Wiwanitkit S, Wiwanitkit V. Afebrile dengue: an easily forgotten manifestation. Ann Trop Med Public Health. 2013;6:686.
Sriram Pothapregada psriram_ped@yahoo.co.in

1 Department of Pediatrics, Indira Gandhi Medical College and Research Institute, Puducherry 605009, India 